\title{
THE COMPARISON OF EFFECT OF ENDOTRACHEAL INTUBATION WITH VIDEO LARYNGOSCOPY VERSUS DIRECT LARYNGOSCOPY ON HEMODYNAMICS RESPONSE AND STRESS RESPONSE
}

\author{
Buyukyildirim A. ${ }^{1}$, Koksal C. ${ }^{2}$, Turkmen U.A. ${ }^{3}$, Kesici S. ${ }^{3}$, Cakirgoz M. ${ }^{2}$, Yildirmak S. ${ }^{4}$
}

${ }^{1}$ Hınıs Sehit Yavuz Yurekseven State Hospital, Dept of Anaesthesiology \& Intensive Care, Erzurum, Turkey, ${ }^{2}$ Okmeydani Training and Research Hospital, Dept of Anaesthesiology \& Intensive Care, Istanbul, Turkey, 3University of Giresun, Dept of Anaesthesiology \& Intensive Care, Giresun, Turkey, ${ }^{4}$ University of Giresun, Department of Clinical Biochemistry, Giresun, Turkey

\section{Background of Study}

In the study, the effects of endotracheal intubation performed with McGRATH video laryngoscopy and direct laryngoscopy under general anesthesia on cardiovascular parameters as well as on cortisol response, one of the stress response effects of intubation were evaluated.

\section{Materials and methods}

The study was conducted with 60 patients who were 18-65 years old and in ASA I-II risk group, who would undergo an operation other than cranial and cardiac surgery in elective conditions. The cases were randomly separated in two groups as Macintosh laryngoscopy $(n=30)$ and McGRATH ${ }^{\circledR}$ series-5 video laryngoscopy $(n=30)$. Intubation was performed after induction when Bispectral index value is 40. Systolic blood pressure (SBP), diastolic blood pressure (DBP), mean blood pressure (MBP), heart rate (HR), blood cortisol levels in terms of stress response were measured 10 minutes before induction and at the 10th, 20th and 30th minutes after intubation. The patients were evaluated for sore throat, hoarseness, swallowing difficulty and blood swab in the intubation tube at the exit from recovery room and after 24 hours. In the evaluation of sore throat Numeric Rating Scale was used $(0-1=$ no pain; 2-4=mild pain, $5-7=$ moderate pain, $8-10=$ severe pain).

\section{Results}

No difference was observed in the groups with regards to complication. Blood was not determined in the intubation tube of the patients in McGRATH video laryngoscopy group. But blood was determined in the intubation tubes of 11 patients in Macintosh laryngoscopy group and statistical discrepancies were determined between groups. In the evaluation of sore throat, it was higher only at the 24th hour after operation in Macintosh than the other group. SBP, DBP, MBP, HR values of McGRATH group were statistically lower at the $1 \mathrm{st}$ and 5 th minutes after intubation. The cortisol levels of McGRATH group were lower at the 10th and 20th minutes after intubation. But cortisol levels at the 30th minute were similar.

\section{Discussion and conclusion:}

McGRATH video laryngoscopy provides a better field of view than Macintosh laryngoscopy. Hemodynamics response to intubation is decreased in McGRATH group. Sore throat, swallowing difficulty, blood swab were less in McGRATH video laryngoscopy group. Besides, cortisol response was also determined lower in McGRATH video laryngoscopy group. As a result, we consider that McGRATH video laryngoscopy may be used in the airway management in the patients especially sympathetic discharge is risky. 